\title{
The Effects of Spatial Scale on Trophic Interactions
}

\author{
Johan Van de Koppel, ${ }^{1 *}$ Richard D. Bardgett, ${ }^{2}$ Janne Bengtsson, ${ }^{3}$ \\ Claudino Rodriguez-Barrueco, ${ }^{4}$ Max Rietkerk, ${ }^{5}$ Martin J. Wassen, ${ }^{5}$ and \\ Volkmar Wolters ${ }^{6}$
}

\begin{abstract}
${ }^{1}$ Netherlands Institute of Ecology (NIOO-KNAW), Centre for Estuarine and Marine Ecology, P.O. Box 140, 4400 AC Yerseke, The Netherlands; ${ }^{2}$ Institute of Environmental and Natural Sciences, Lancaster University, Lancaster LA1 4YQ, United Kingdom; ${ }^{3}$ Department of Ecology and Evolutionary Research, Swedish University of Agricultural Sciences, P.O.Box 7072,75007 Uppsala, Sweden; ${ }^{4}$ Instituto de Recursos Naturales y Agrobiología, CSIC, P.O. Box 25737071 Salamanca, Spain; ${ }^{5}$ Copernicus Institute for Sustainable Development and Innovation, Environmental Sciences, University Utrecht, P.O. Box 80115, 3508 TC Utrecht, The Netherlands; ${ }^{6}$ Department of Animal Ecology, Justus Liebig-University, Heinrich-Buff-Ring 26-32 35392 Giessen, Germany
\end{abstract}

\begin{abstract}
Food chain models have dominated empirical studies of trophic interactions in the past decades, and have lead to important insights into the factors that control ecological communities. Despite the importance of food chain models in instigating ecological investigations, many empirical studies still show a strong deviation from the dynamics that food chain models predict. We present a theoretical framework that explains some of the discrepancies by showing that trophic interactions are likely to be strongly influenced by the spatial configuration of consumers and their resources. Differences in the spatial scale at
\end{abstract}

\section{INTRODUCTION}

Ecological theory on food web dynamics is to a large extent based on simple food chains (Oksanen and others 1981) or simple community modules (Holt 1997). In food chain models, trophic interactions between species or groups of species are supposed to form chain-like structures, such as plant-herbivore-predator, or detritus-detrivorepredator chains. These models have been particularly successful in providing a theoretical framework for scientific debates on "why the world is

Received 24 September 2003; accepted 3 August 2004; published online 21 October 2005.

*Corresponding author; e-mail: J.vandeKoppel@nioo.knaw.nl which consumers and their resources function lead to uncoupling of the population dynamics of the interacting species, and may explain overexploitation and depletion of resource populations. We discuss how changed land use, likely the most prominent future stress on natural systems, may affect food web dynamics by interfering with the scale of interaction between consumers and their resource.

Key words: spatial scale; predator-prey interaction; consumer-resource interaction; trophic cascade; land use. green" (Hairston and others 1960; Polis 1999), on trophic cascades (Carpenter and others 1985), or on "bottom-up" and "top-down" control in natural communities (Power 1992). Food chain models have been much less successful in providing predictions that resemble the dynamics of natural ecosystems (Pace and others 1999), apart from examples from lake ecosystems or small holes in trees (Strong 1992; Kitching 2001). This severely limits the applicability of food web theory for assessing the consequences of future anthropogenic changes, such as those caused by changed land use.

A number of reasons were suggested for the discrepancies between food chain models and the dynamics of natural ecosystems (Chase 2000; Polis and others 2000). Obviously, most natural com- 
munities consist of more complex interactions than simple food webs. They form complex structures, where multiple indirect effects obscure direct effects of trophic interactions. Furthermore, food web theory depends strongly on the validity of lumping large numbers of species into functional groups, which has frequently been criticized (Persson 1999; Polis and others 2000). Secondly, prey are often not uniformly edible, and consumption may lead to changes in prey defences and stoichiometry (Loladze and others 2000; Schmitz and others 2000). Finally, studies of trophic cascades in terrestrial systems suggest that interactions occurring over large spatial scales lead to deviations from the predictions of consumer-resource (predator-prey or plant-herbivore) models (Jefferies 2000; Sanchez-Pinero and Polis 2000).

Although the effects of food web complexity and prey edibility received significant attention (McCann and others 1998; Loladze and others 2000; Grover 2003), much less is known of the implication of the spatial scale of consumer-resource interactions for understanding the dynamics of natural communities. In this paper, we provide a simple framework that helps in understanding some important deviations between observed food web dynamics and the dynamics predicted by simple predator-prey or food-chain models. This framework is based on consideration of qualitative differences in the scale of distribution of either consumer or resource. We further discuss how future changes in land use may affect food web dynamics by interfering with the functional scale of trophic interactions. We do not intend to be comprehensive in our approach. Rather, we aim to show that including spatial aspects of consumerresource relations will significantly advance our understanding of species interaction and food web dynamics in both natural and disturbed ecosystems.

\section{Spatial Aspects of Consumer-Resource INTERACTIONS}

Classical models of consumer-resource interactions assume a homogeneous distribution of both the consumer and the resource. In most natural ecosystems, however, resources are patchily distributed across space. As a consequence, a consumer may consider a part of its habitat unsuitable, as the density of resource is too low, whereas in other parts resource availability is sufficiently high. Moreover, a small patch of edible plants might be considered as "not worth the effort" by a large herbivore such as a horse, which observes and examines its habitat on a scale of meters. A mouse, which observes its habitat at a much finer scale, may consider the patch as sufficiently attractive. We refer to the observational window of the consumer as the grain at which a consumer examines its habitat (conform Milne 1992). Consumers cover significant distances in search of food. Movements, however, are virtually always limited in spatial extent, due to costs associated with mobility. We define the extent of the consumer habitat as the size of the area that is covered by the consumer when searching for resources (Milne 1992).

Logically, the observational grain of a consumer is finer than the extent of its habitat. Hence, the grain and extent define the lower and upper limits of a spatial scale range along which a consumer exploits the environment, which we will from now on refer to as the "functional range" of the consumer. In Figure 1, we have arbitrarily depicted this range along a scale axis, ranging from a fine scale of $\mathrm{cm}^{2}$ to a large scale of several $\mathrm{km}^{2}$. In a similar manner, we depicted the spatial characteristics of the resource along this axis. The lower boundary represents the smallest patch size of the resource. In the case of plants as a resource, patch size may be defined as the size of an individual plant. The upper boundary of the resource scalerange in Figure 1 is determined by the scale beyond which the resource cannot be considered, from a population dynamical viewpoint, as a single population. At scales below this limit, resources are considered a single linked population or pool. Beyond this scale, multiple populations or pools are involved, which are considered as separate (meta-) populations. These populations are linked only via the consumer. For the sake of simplicity, we will call this upper bound the extent of the resource habitat. Note that consumers can move between different resource habitats if the extent of movements of the consumer is larger than the extent of the resource habitat, as is depicted in Figure 1.

Most theoretical models on consumer-resource interaction do not consider spatial heterogeneity (Holt 2002). They implicitly assume that no resources are left unused because of observational limits or movement restrictions. This implies that the observational grain of the consumer is equal to the size of the smallest resource patch, and that the extent of movements of the consumer equals the extent of the resource habitat, as in Figure 2A. An example of such a system would be a small homogeneous lake. Under these conditions, we expect the consumer and its resource to be perfectly coupled, and to behave as is predicted in the classical models. Increase of the consumer population will lead to a decrease in resource 


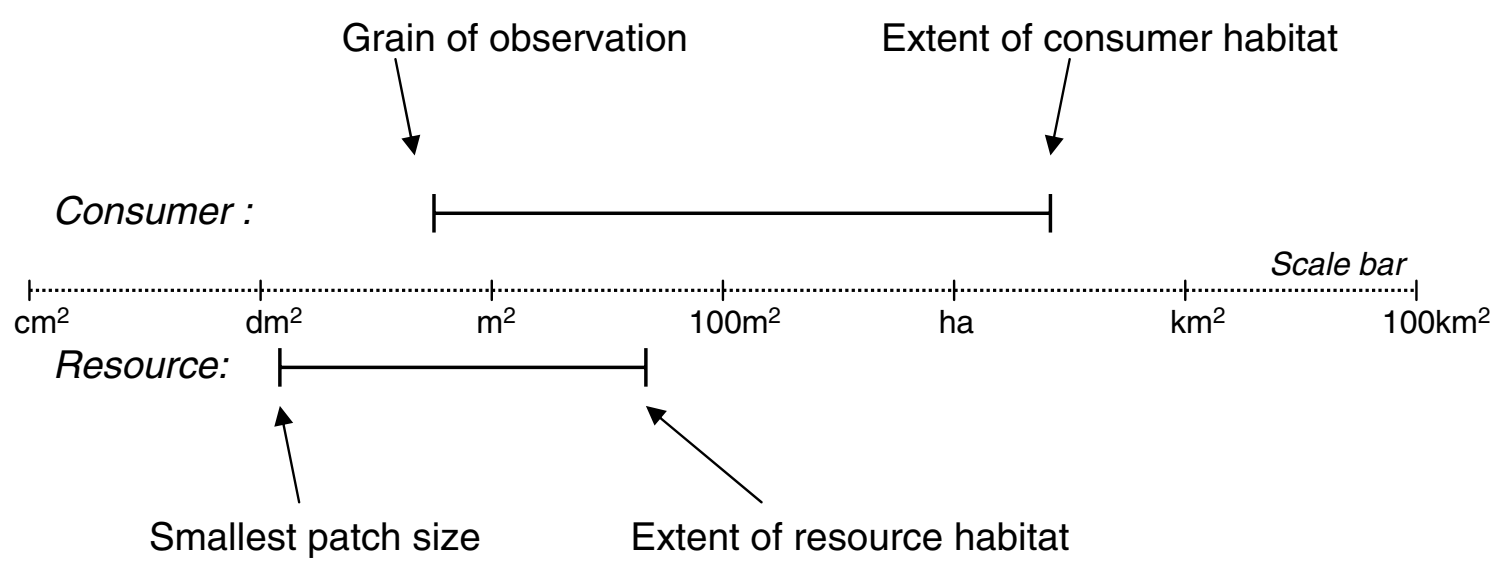

Figure 1. Functional scale range at which a consumer (upper solid bar) and its resource (lower solid bar) function. The consumer range is bounded by the grain of observation of the consumer, and the extent of the consumer's habitat. The lower bar (resource) is bounded by the size of the smallest patches of the resource (minimally the size of an individual), and the extend of the habitat of the resource.

\section{A: Normal cascade}

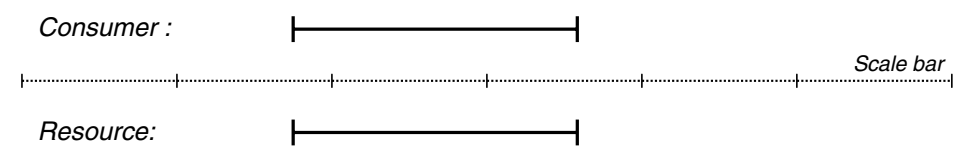

B: Apparent competition in space

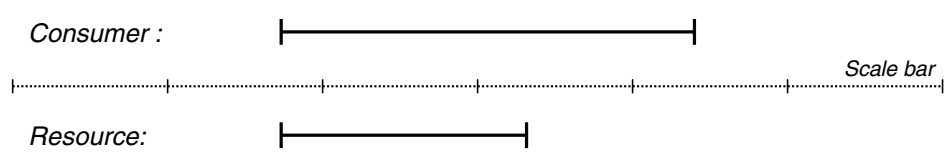

\section{C: Small patch refuge}

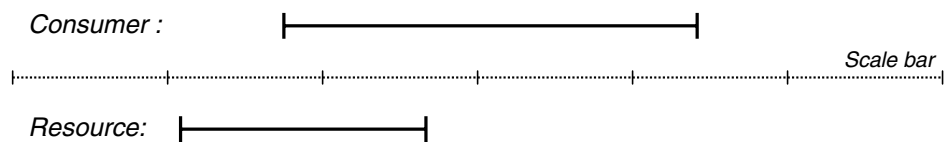

Figure 2. Three possible configurations of the functional ranges of the consumer and its resource. A The functional ranges of consumer and resources are equal, resulting in a perfectly coupled consumer-resource interaction. B The extent of the consumer habitat exceeds the extent of the resource habitat. $\mathbf{C}$ As in $\mathbf{B}$, but the grain of observation of the consumer is larger than the lowest patch size of the resource. Both B and C lead to deviations of the interaction from that predicted by food chain models.

availability, but the consumer will be unable to overexploit the resource, as it would lead to it's own demise.

\section{Scale Deviation between Consumer and RESOURCE}

Scale deviation between the consumer and its resource is very common. In many (but certainly not all) consumer-resource interactions, the consumer is more mobile than its resource. The extent of movement of an herbivore may cover many square kilometres, and is often (but not always) larger than the spatial scale at which plant populations influence each other directly. This is reflected on the scale axis in Figure 2B, where the extent of movement of the consumer stretches well beyond the extent of the resource habitat. In this situation, resource patches that are too far apart to affect each other directly may still influence each other via the consumer. This situation is similar to "apparent competition", where different populations influence each other via a common predator (Holt 1977). Apparent competition leads to uncoupling 
of the population dynamics of the consumer and the local resource population, as the dynamics of the consumers depend on a multitude of resource populations in space. Apparent competition may lead to overexploitation and even depletion of one of the local resource populations, as the consumer is subsidized by other populations (Holt 1977). Carry-over effects between resource patches or areas are predicted to amplify differences in resource production rates between patches, and lead to the formation of spatial patterns of resource-rich and degraded patches (de Roos and others 1998). Carry-over effects as a consequence of spatial "subsidies" have, for instance, been reported to cause degradation in the Arctic tundra (Jefferies 2000), where a change in food availability at the winter grounds of geese caused pattern formation and even degradation of the habitats used by the geese during the summer. Similar depletion of prey population densities was observed by Polis and Hurd (1995) in desert island ecosystems, where spiders, supported by large inputs of marine detritus food, suppressed herbivorous prey. Such long-term depletion of resources is prevented in fully coupled consumer-resource interactions (Figure 2A), as the consumer densities would collapse as a consequence of lack of food.

Despite the generally higher mobility in consumers such as herbivores, examples of depletion of vegetation due to overgrazing are not very common in natural grasslands. This is likely the result of a similar uncoupling of resource and consumer dynamics at fine scales. For example, consumers that move great distances are likely to observe their resources on a coarse scale, neglecting small patches of food (Ritchie and Olff 1999; Holt 2002). This is depicted in Figure 2C, where the size of the smallest patches of resource is below the grain at which the consumer observes or assesses the landscape. The consumer, because of the costs associated with the interruption of movement, ignores fine-scale patches. As a consequence, resources are protected against consumption in fine-scale patches, lowering the interaction strength between resource and the consumer, and low resource densities. This effect is captured by the Holling type 3 functional response, and prevents complete depletion of the resource by the consumer (for example, Yodzis 1989). Hence, discrepancies in the scale of utilization of a landscape and the scale of heterogeneity of the resource can cause both depletion and overexploitation of the resource, but may also protect the resource against overexploitation (Van de Koppel and others 2002).
The above examples are by no means comprehensive. Many more deviations from the configuration of Figure 2A are possible. For instance, most sessile bivalves are filter feeders that consume algae from the water. Flow and wave energy result in significant movement and mixing of algae in the water, and hence may transport algae over great distances. Such a system would be an example of an interaction where the extent of the resource exceeds the extent of the consumer. To fully cover possible effects of scale discrepancies on natural communities, our categorization needs to be extended to three-link chains or even food webs. This is beyond the scope of this paper.

Critical in understanding the effects of spatial scale on trophic interactions is that consumption rates are determined by limitations on spatial movements of resources and consumers, as well as by properties such as handling times. Movement constraints strongly influence stability and species persistence in model food webs (Hassell and others 1991, 1994). If movements are slow, subsidies from the surrounding habitats by means of resource or consumers are low, which has a stabilizing influence on the population dynamics of the involved species. If movements are fast and large, subsidies dominate local population dynamics, and may lead to local extinction of either consumers or resource (Huxel and McCann 1998). Theoretical studies emphasize the potential for spatial interactions to stabilize predator-prey (de Roos and others 1998), plant-herbivore (Van de Koppel and others 2002), and plant-water interactions (Van de Koppel and Rietkerk 2004) on larger spatial scales. Differences in the rate and extent of spatial movements between resource and consumer are a common property of these models, explaining the emergent stability.

\section{Human Interference with Scale Aspects of Predator-Prey Interactions}

Humans have in major ways modified landscape patterns and land use (Vitousek and others 1997). The most important aspects in the present context are: (1) restrictions of movements of consumers, for instance by fencing grazing herbivores; and (2) modifying, usually decreasing, the heterogeneity of resources, for instance by monoculture forestry and agriculture. The first way corresponds to decreasing the extent of consumer habitat, whereas the second corresponds to a decreased spatial extent of the resource. Both types of interference may lead to consumer and resource populations becoming 


\section{A: Restriction of consumer}

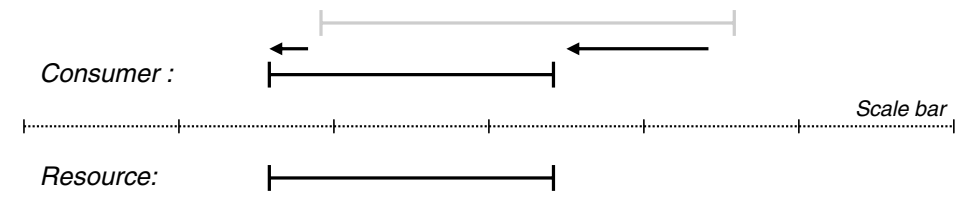

B: Homogenisation of resource habitat

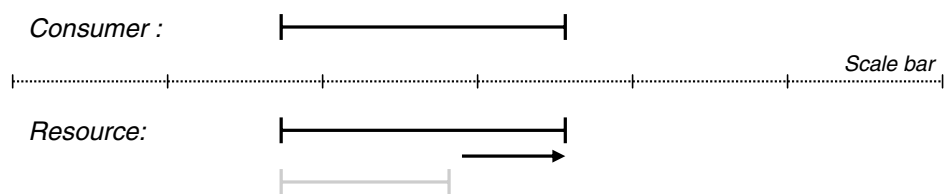

Figure 3. Effects of human interference on consumer-resource interaction by A restriction of the mobility of the consumer, for instance by fragmenting the habitat of the consumer, and $\mathbf{B}$ by homogenization of the resource habitat, which is a common feature of agricultural landscapes.

more closely linked, a condition favoring species that exert strong control over their resources. We will discuss both cases in detail below.

In many grasslands, the natural behavior of large grazers is large-scale movement, ensuring that any locality is subjected to pulses of intense grazing. This leads to mosaic grasslands that can sustain high grazer densities. Humans have, by intensifying land use, fenced domesticated herbivores into smaller plots. As a result, grazing became intense and continuous, forcing animals to utilize small patches that they would otherwise avoid. This restriction of consumer movement by fencing animals into smaller areas synchronizes consumer and resource dynamics (Figure 3A) and leads to larger risks of severe grazing effects and trampling damage. The restricted movement in domestic animals has created exactly the conditions required for severe herbivore effects on semi-arid grasslands (Milne 1992; Van de Koppel and others 2002).

Monoculture agriculture and forestry is ubiquitous, although mixed-species ( $2-3$ species, usually) forestry is becoming more common. It is well known that monocultures often lead to increased pest problems (for example, Juska and others 1997). In the present context, agricultural practices favor resource homogenization, which increases resource patchiness to spatial scales above the observational grain of consumers such as pest species (Figure 3B). Because pests often are good dispersers, this intensifies the interactions between pests and their resource species. Furthermore, humans have decoupled the dynamics of resources and consumers by taking control of the renewal of resources. By constantly adding new generations of the same crops to agricultural systems, irrespective of consumer (that is, pest) densities, the coupling of consumers and resources in homogenous systems is broken. The effect is often pest outbreaks that have to be managed by pesticides (for example, Juska and others 1997). Homogenization of agricultural landscapes may even affect control of pest outbreaks by higher trophic levels. For example, large areas of spring cereals enhance populations of pests such as the bird-cherry oat aphid, a major pest in Scandinavia and Western Europe. In mosaic small-scaled landscapes, generalist natural enemies can control or at least reduce pest outbreaks, but their effectiveness is reduced as landscape heterogeneity decreases (Ostman and others 2001). The natural enemies require habitats outside the fields for their persistence, and the more of them that are present in the field when the aphids colonize, the better the biological control.

Human activities may lead to changes in the structure of food webs by interfering with the functional range of the predator or prey. One of the best examples of this is the abovementioned case where the extent of domesticated herbivores is restricted by fencing. Most herbivores are naturally selective feeders, preferentially feeding on more palatable plant species within a plant community (Bardgett and Wardle 2003). In free-range ecosystems, herbivores have the potential to move across landscapes, selecting areas of palatable forage and obtaining a balanced diet. This provides a good opportunity to maximize energy intake (Wallisdevries and others 1999). In most human-created landscapes, the size of nature reserves is typically small and habitat diversity is low, limiting the subsistence potential for herbivore populations (Wallisdevries 1996). In such fragmented areas (small size and low connectivity) the amount and 
diversity of resource patches is likely to be low. This may on the one hand limit the diet of herbivores as the variety of suitable resources is reduced. On the other hand, food limitation may force herbivores to consume unfavorable plant species. Both strongly affect the food choice of herbivores, and hence affect food web structure. Restriction of herbivore movement and increased grazing pressure within a locality may also influence food web structure in an indirect way, for instance by affecting decomposer communities and their relationship with the vegetation (Bardgett and Wardle 2003).

\section{Managing Trophic Interactions in a Changing World}

A major future impact on (semi-) natural ecosystems will come from changed land use, leading to destruction, fragmentation or homogenization of habitat. Current developments in metapopulation theory stress that endangered species can survive at a regional level if local extinctions are compensated by recolonization from other populations. For this reason, modern landscape and nature management focuses on restoring connectivity between fragmented landscapes. Our review suggests that the effects may be two-fold. By broadening the resource base available to consumers, linking of nature reserves may uncouple the population dynamics of resource and consumer, which in turn may prevent consumer population crashes. On the other hand, spatial subsidies that result from linking reserves may increase local densities of consumers, leading to increased predation and local extinction of resource populations, as has been described for insect host-parasitoid systems (Holt and Lawton 1993), seed predation by rodents (Orrock and others 2003), and for breeding geese on arctic islands (Madsen and others 1992). For those reasons, knowledge of the intrinsic spatial scale and potential rates of the interaction between consumers and their resources is pivotal for nature conservation to be effective.

\section{ACKNOWLEDGEMENTS}

We thank Martijn Bezemer, Jeff Harvey, Wim van der Putten, Peter de Ruiter, and two anonymous reviewers for constructive comments and suggestions. This paper results from a exploratory ESF workshop on "Trophic Interactions in a Changing World", at Texel, The Netherlands (2002). The research of M.R. is supported by a grant from the Research Council Earth and Life Sciences of the Netherlands Organization of Scientific Research
(NWO-ALW). This is contribution 3334 of the Netherlands Institute of Ecology.

\section{REFERENCES}

Bardgett RD, Wardle DA. 2003. Herbivore mediated linkages between aboveground and belowground communities. Ecology 84:2258-68.

Carpenter SR, Kitchell JF, Hodgson JR. 1985. Cascading trophic interactions and lake productivity. Bioscience 35: 634-9.

Chase JM. 2000. Are there real differences among aquatic and terrestrial food webs? Trends Ecol Evol 15:408-12.

De Roos AM, McCauley E, Wilson WG. 1998. Pattern formation and the spatial scale of interaction between predators and their prey. Theor Popul Biol 53:108-30.

Grover JP. 2003. The impact of variable stoichiometry on predator-prey interactions: a multinutrient approach. Am Nat 162:29-43.

Hairston NG, Smith FE, Slobodkin LB. 1960. Community structure, population control, and competition. Am Nat 94:425.

Hassell MP, Comins HN, May RM. 1991. Spatial structure and chaos in insect population-dynamics. Nature 353:255-8.

Hassell MP, Comins HN, May RM. 1994. Species coexistence and self-organizing spatial dynamics. Nature 370:290-2.

Holt RD. 1977. Predation, apparent competition, and the structure of prey communities. Theor Popul Biol 12:197-229.

Holt RD. 1997. Community modules. In: A.C. Gange and V.K. Brown, Eds. Multitrophic Interactions in Terrestrial Ecosystems, 36th Symposium of the British Ecology Society. Blackwell Science. p. 333-349.

Holt RD. 2002. Food webs in space: on the interplay of dynamic instability and spatial processes. Ecol Res 17:261-73.

Holt RD, Lawton JH. 1993. Apparent competition and enemyfree space in insect host-parasitoid communities. Am Nat 142:623-45.

Huxel GR, McCann K. 1998. Food web stability: the influence of trophic flows across habitats. Am Nat 152:460-9.

Jefferies RL. 2000. Allochthonous inputs: integrating population changes and food-web dynamics. Trends Ecol Evol 15:19-22.

Juska A, Busch L, Tanaka K. 1997. The blackleg epidemic in Canadian rapeseed as a "normal agricultural accident". Ecol Appl 7:1350-6.

Kitching RL. 2001. Food webs in phytotelmata: "Bottom-up" and "top-down" explanations for community structure. Annu Rev of Entomol 46:729-60.

Loladze I, Kuang Y, Elser JJ. 2000. Stoichiometry in producergrazer systems: linking energy flow with element cycling. Bull Math Biol 62:1137-62.

Madsen J, Bregnballe T, Hastrup A. 1992. Impact of the Arctic fox Alopex-Lagopus on nesting success of geese in Southeast Svalbard, 1989. Polar Res 11:35-9.

McCann KS, Hastings A, Huxel GR. 1998. Weak trophic interactions and the balance of nature. Nature 395:794-8.

Milne BT. 1992. Spatial aggregation and neutral models in fractal landscapes. Am Nat 139:32-57.

Oksanen L, Fretwell SD, Arruda J, Niemela P. 1981. Exploitation ecosystems in gradients of primary productivity. Am Nat 1 18:240-61. 
Orrock JL, Danielson BJ, Burns MJ, Levey DJ. 2003. Spatial ecology of predator-prey interactions: corridors and patch shape influence seed predation. Ecology 84:2589-99.

Ostman O, Ekbom B, Bengtsson J, Weibull AC. 2001. Landscape complexity and farming practice influence the condition of polyphagous carabid beetles. Ecol Appl 11:480-8.

Pace ML, Cole JJ, Carpenter SR, Kitchell JF. 1999. Trophic cascades revealed in diverse ecosystems. Trends Ecol and Evol 14:483-8.

Persson L. 1999. Trophic cascades: abiding heterogeneity and the trophic level concept at the end of the road. Oikos 85:385-97.

Polis GA. 1999. Why are parts of the world green? Multiple factors control productivity and the distribution of biomass. Oikos 86:3-15.

Polis GA, Hurd SD. 1995. Extraordinarily high spider densities on islands - flow of energy from the marine to terrestrial food webs and the absence of predation. Proceedings of the National Academy of Sciences of the United States of America 92:4382-6.

Polis GA, Sears ALW, Huxel GR, Strong DR, Maron J. 2000. When is a trophic cascade a trophic cascade? Trends Ecol Evol 15:473-5.

Power ME. 1992. Top-down and bottom-up forces in food webs - do plants have primacy. Ecology 73:733-6.
Ritchie ME, Olff H. 1999. Spatial scaling laws yield a synthetic theory of biodiversity. Nature 400:557-60.

Sanchez-Pinero F, Polis GA. 2000. Bottom-up dynamics of allochthonous input: direct and indirect effects of seabirds on islands. Ecology 81:3117-32.

Schmitz OJ, Hamback PA, Beckerman AP. 2000. Trophic cascades in terrestrial systems: a review of the effects of carnivore removals on plants. Am Nat 155:141-53.

Strong DR. 1992. Are trophic cascades all wet - differentiation and donor-control in speciose ecosystems. Ecology 73:747-54.

Van de Koppel J, Rietkerk M. 2004. Spatial interactions and resilience in arid ecosystems. Am Nat 163:113-121.

Van de Koppel J, Rietkerk M, van Langevelde F, Kumar L, Klausmeier CA, Fryxell JM, Hearne JW, van Andel J, de Ridder N, Skidmore A, Stroosnijder L, Prins HHT. 2002. Spatial heterogeneity and irreversible vegetation change in semiarid grazing systems. Am Nat 159:209-218.

Vitousek PM, Mooney HA, Lubchenco J, Melillo JM. 1997. Human domination of Earth's ecosystems. Science 277:494-9.

Wallisdevries MF. 1996. Nutritional limitations of free-ranging cattle: the importance of habitat quality. J Appl Ecol 33:688-702.

Wallisdevries MF, Laca EA, Demment MW. 1999. The importance of scale of patchiness for selectivity in grazing herbivores. Oecologia 121:355-63.

Yodzis P. 1989. Introduction to theoretical ecology. Harper $\delta$ Row, New York, USA. 